IZA DP No. 9551

State Dependence in Welfare Benefits in a Non-Welfare Context

Sinem H. Ayhan

Selin Pelek

December 2015 


\title{
State Dependence in Welfare Benefits in a Non-Welfare Context
}

\author{
Sinem H. Ayhan \\ IZA
}

Selin Pelek

Galatasaray University

\section{Discussion Paper No. 9551 \\ December 2015}

\author{
IZA \\ P.O. Box 7240 \\ 53072 Bonn \\ Germany \\ Phone: +49-228-3894-0 \\ Fax: +49-228-3894-180 \\ E-mail: iza@iza.org
}

\begin{abstract}
Any opinions expressed here are those of the author(s) and not those of IZA. Research published in this series may include views on policy, but the institute itself takes no institutional policy positions. The IZA research network is committed to the IZA Guiding Principles of Research Integrity.

The Institute for the Study of Labor (IZA) in Bonn is a local and virtual international research center and a place of communication between science, politics and business. IZA is an independent nonprofit organization supported by Deutsche Post Foundation. The center is associated with the University of Bonn and offers a stimulating research environment through its international network, workshops and conferences, data service, project support, research visits and doctoral program. IZA engages in (i) original and internationally competitive research in all fields of labor economics, (ii) development of policy concepts, and (iii) dissemination of research results and concepts to the interested public.
\end{abstract}

IZA Discussion Papers often represent preliminary work and are circulated to encourage discussion. Citation of such a paper should account for its provisional character. A revised version may be available directly from the author. 


\section{ABSTRACT}

\section{State Dependence in Welfare Benefits in a Non-Welfare Context ${ }^{*}$}

This study contributes to the ongoing debate about welfare dependency centered on the western societies through an empirical analysis, within the context of a developing country. It examines state dependence in social assistance benefit receipt using longitudinal data from Turkey, where benefit receipt and persistence rates have witnessed a significant increase since the last decade. Identification is achieved by dynamic random effects probit models, controlling for unobserved heterogeneity and endogenous initial conditions. Particularly, Wooldridge's (2005) estimator and its extensions are applied for achieving consistent and correct estimates of state dependence. In order to check for sensitivity, the results are compared with the results from Heckman's (1981) reduced form approach. Both estimators enable us to deal with the potential bias due to the short panel length. It is found that the benefit receipt of the last year increases the likelihood of benefit receipt in the current year by 17 to 22 percentage points. This evidence suggests that state dependence in social assistance might also be a relevant phenomenon for developing countries.

JEL Classification: $\quad 130,138, \mathrm{~J} 18, \mathrm{C} 23$

Keywords: $\quad$ social assistance benefits, state dependence, endogenous initial conditions, dynamic random effects models

Corresponding author:

Sinem H. Ayhan

IZA

P.O. Box 7240

53072 Bonn

Germany

E-mail: ayhan@iza.org

\footnotetext{
* We would like to thank Alpaslan Akay, Lorenzo Cappellari, Nail Dertli and Jeffrey M. Wooldridge for their valuable and helpful suggestions.
} 


\section{Introduction}

There is an ongoing debate in the welfare economics literature on benefit dependency. The discussions revolve around countries with generous social assistance schemes, and focus on Northern Europe, particularly in Germany, the United Kingdom and Scandinavian regions. The question central to this literature is whether the generosity of the social assistance system causes dependence in benefit receipt. This question determines whether benefit receipt in the current period makes the beneficiary more likely to receive future benefits. Technically speaking, it makes an attempt to ascertain state dependence in benefit receipt. Empirical evidence suggests a considerable level of state dependence in the aforementioned countries that are considered for discussion in this matter (see Andren and Andren, 2013, Cappellari and Jenkins, 2014; Hansen et al., 2014; Königs, 2014).

The related literature from developing countries, mostly from Latin America and Africa, mainly focuses on the evaluation of anti-poverty social transfer programs (e.g., Baird et al., 2011; Duflo, 2003, Edmonds and Schady, 2012, Manacorda et al., 2009). Similarly, the available literature in Turkey largely studies the poverty alleviation role of social assistance benefit: 1 . To the best of our knowledge, none of the studies in this small literature have attempted to focus on the dynamics of social assistance benefits. This could be partly because state dependence is not an issue in developing countries, given a short spell of the benefits, and partly because of the unavailability of longitudinal data. The current study contributes to the literature by analyzing the dynamics of social assistance benefits within the state dependence framework, in a developing country context. It employs the data obtained from a case study conducted in Turkey, where the role of social assistance benefits in the welfare and political arena has witnessed an increase over the last decade. This period corresponds to a new term of government, led by a single party that came into power in November 2002, after a domestically-

\footnotetext{
${ }^{1}$ In a qualitative analysis of social policies in Turkey, Buğra $(2009)$ considers social assistance benefits as an essential tool for poverty alleviation. SSeker (2008), comparing the probability of exiting from poverty before and after transfer receipt, argues the effective role of social transfers in reducing the poverty. Aytaç (2014), on the other hand, draws attention to the political preferences in allocating the social transfers across multiple electoral districts. In relation to this, in an empirical analysis on the identification of target groups, Karagöl et al. (2013) discusses the need for revisions in eligibility criteria for benefit receipt.
} 
originated economic crisi: 2

Having experienced noticeable changes in the field of social assistance, both in quantitative and qualitative term, Turkey assumes an interesting position in relation to the investigation of dynamics of social assistance benefits. According to the Ministry of Finance records, social expenditures financed by public sources increased fifteen-fold and reached 32.9 billion Turkish Liras (about 10.1 billion Euro) in 2014. The share of social assistance expenditures in GDP rose to 1.73 percent, while it was only 0.5 percent in $2002^{3}$. Currently, 3 million households, accounting for 15.6 percent of total number of households, receive some type of social transfers 4 . Moreover, we observed a steady increase in the welfare participation rate in Turkey, contrary to the downward trend in developed countries such as Canada, the United Kingdom and the United States5 The increase in the welfare participation rate in the 2005-2012 period is associated with a remarkably high rate of persistence (of around 80 percent), despite a relatively low level of and constant trend in the entry rate (Figure 4). The study seeks to determine the extent of high persistence rate in Turkey that can be explained by state dependence.

This question is of particular importance from a policy-making perspective, especially in a country like Turkey that lacks a well-targeted and welldesigned social safety net. The absence of nationwide rules set for benefit allocation leaves a large room for discretionary policies. The drawbacks in the system might potentially explain for the high rate of persistence in benefit receipt. On the other hand, the relationship between the current and future benefit receipt can be attributed to the observed and unobserved characteristics of the individual factors. If these factors contribute to the observed persistence rate, then policies may be less effective in inducing exits from social assistance and in subsequently reducing persistence and state dependence. The study, therefore, emphasizes on the need to disentangle the structural state dependence from the spurious components that emerge from individual heterogeneity.

\footnotetext{
${ }^{2}$ Justice and Development Party has recently, one more time won the general elections held on November 1st, 2015 as a single government for a four-year period.

${ }^{3}$ Nevertheless, the ratio of social expenditures to GDP is still below the EU and OECD average, 2.5 and 2.3 percent, respectively (OECD, 2014).

${ }^{4}$ See the link for the reference: http://www.maliye.gov.tr/KonusmaSunumlari/ SunumMerkezi/index.html?ktp=2015YBSK

${ }^{\breve{S} S e e} \widehat{\text { Figure 1 } 1}$ for Turkey and Hansen et al. (2014); Cappellari and Jenkins (2008); Scholz et al. (2009) for above-mentioned countries.
} 
To accomplish this, the study employs a series of dynamic random effects probit models that facilitate the control for unobserved heterogeneity. We use annual panel data from the 'Survey of Income and Living Conditions', for the period 2006-2012. Identification of structural state dependence emphasizes on the need to handle endogenous initial conditions, which if undetected could lead to a bias in parameter estimates. The study deals with this problem through the employment of two empirical methods proposed by Wooldridge (2005) and Heckman (1981). Several extensions of the Wooldridge's approach are being employed, following Rabe-Hesketh and Skrondal (2013), to avoid concerns raised by Akay (2012) regarding the potential bias in the Wooldridge estimates that might emerge from a shorter time span of panel.

The results suggest that failure to control for the endogenous initial conditions leads to a serious overestimate of the state dependence. The results suggest significant evidence of state dependence in social assistance benefit receipt, even after controlling for unobserved heterogeneity and endogenous initial conditions. The results are quite consistent among different specifications. This consistency ensures the feasibility of a state dependence analysis, based on a short panel, which is particularly important for developing countries that lack long panel data. It is found that benefit receipt in previous year increases the average likelihood of benefit receipt in the current year by 17 to 22 percentage points. This finding is at least 3 percentage points larger than the results reported for the United Kingdom and Germany Cappellari and Jenkins, 2014; Königs, 2014). The persistence rate is also estimated as higher, whereas the study finds a substantially lower entry rate in Turkey relative to these countries. Taken together, the strong evidence of structural state dependence in benefit receipt points out a high potential for a successful policy reform that would result in a reduction in the persistence rate.

The rest of the paper is organized as follows. Section 2 presents the data and provides descriptive statistics for trends in benefit receipt and transition rates of different sub-populations. Section 3 introduces the empirical models. The estimates and predictions are discussed in Section 4, and Section 5 concludes the study. Appendix A provides an institutional background about the social assistance system in Turkey. 


\section{Data}

For the analysis of state dependence in social assistance benefit receipt, the data is obtained from the 'Survey on Income and Living Conditions (SILC)', a representative longitudinal survey of households in Turkey. The panel was initiated in 2006, and the latest survey was made available in 2012. SILC is the first of its kind of panel survey that has been attempted in Turkey. The survey is designed as a rotating panel in which the sample of households and corresponding individuals are traced annually for four consecutive years. The structure design of the panel facilitates replacement of one-fourth of the sample by a new one in each year, thus three-fourths of the sample remains unchanged with respect to the previous year.

These samples are collected to gain detailed information on demographic characteristics such as age, education, marital status; labor force characteristics such as employment status, previous work information, income; as well as household characteristics. In a sampled household, all members are individually interviewed and one of the household members (reference person) fills an additional questionnaire regarding the household characteristics. This household-level survey provides relevant information related to social assistance benefits.

The outcome variable of interest indicates whether the reference person within a household is in benefit receipt or not. The study focuses on social assistance schemes aiming at income maintenance rather than income replacement. In particular, the contribution-based social assistance schemes such as unemployment benefits, maternal benefits, sickness allowance and retirement pension are excluded from the analysis. Therefore, the questions regarding non-contributory social transfers received by households, including family and child allowances, housing benefits, and other social benefits in cash and kind, are examined to construct the outcome variablet. As mentioned above, these questions are responded by the reference person of each household. These responses provide the recipient status of every individual, which is determined by their household's recipient status. Therefore, an individual level analysis is conducted based on reference persons, extracting the benefit receipt information from households.

\footnotetext{
${ }^{6}$ See Appendix A for the types of social assistance schemes, eligibility criteria for being in receipt and institutional structure.
} 
Given the household-based eligibility criteria, we might expect that changes in the household composition and size affect the benefit recipient status. We might also expect that individual characteristics of household members are important drivers of the probability of receiving social assistance benefits. For instance, the husband's characteristics in a traditional single-earner household, the birth of a child into a low-income household, or the separation of an income earner from the household are likely to make a change in the self-sufficiency levels, and thus in the benefit recipient status. An individual-level analysis allows us to control for both respondent's and partner's characteristics, as well as to deal with the compositional changes within households through divorce, repartnering, or the entry to adulthood of a dependent child (Cappellari and Jenkins, 2014; Königs, 2014).

The panel used for our analysis, beginning from the year 2006, consists of seven waves. However, every individual can at the most be observed for four consecutive years, as mentioned above. As a focus on the state dependence analysis, the study examines reference persons who were observed for at least two consecutive years during the sample period 7 . The sample is restricted to working age population (aged 15 to 64 ) for ruling out complications regarding the entry into the labor market and old-age pension scheme. The analysis also excludes individuals in full-time education and deletes observations with missing information on one or more control variables. We end up with a final sample of 3,450 individuals (10,239 observations) in the balanced panel and 14,383 individuals $(25,222$ observations) in the unbalanced panel.

\subsection{Descriptive Statistics}

In this subsection, we first present the trend in the share of recipients in total working age population for the period 2005-2012. Figure 1 illustrates a steady increase in the rate of social assistance benefit receipt until 2009, and a relatively constant trend since then (denoted by solid line). It reaches its peak value of 18.8 percent just after the economic crisis year of 2008 , and does not fall significantly in the post-crisis period. It is worthy to note that the period denoting an upward trend in benefit receipt coincides with positive economic growth, except for the year of 2009.

\footnotetext{
${ }^{7}$ The sample will further be restricted to individuals observed over the entire panel period (i.e., four years) as the main regression analysis relies on balanced sample. This issue is elaborated in Section 4.
} 
A breakdown of different social assistance schemes is shown in the same graph. The first category is child benefits comprising cash and/or in kind maternity allowance and conditional cash transfers related to children's health care and education (denoted by long dashed line). The second one is housing benefits, which involve cash allowances related to housing such as renting or home construction (denoted by long dashed-dotted line). The number of respondents reporting the housing benefits receipt are negligible in our sample (less than 1 percent) given the limited scope of these schemes. These benefits play a significant role in certain cases such as earthquake, food disaster or mining accidents. The last category comprises all other social assistance benefits in cash and in kind, financed by public and/or private resources (denoted by dashed line). The incidence of other social assistance benefits is clearly the highest of all the social assistance schemes. However, we observe a slight decrease in the recipient rate of these transfers by 2009, which is associated with a proportional increase in the rate of child benefits recipients.

The rates of benefit receipt by household type are presented in Figure 2. While there is an upward trend for the households with dependent children (aged less than 16), those without dependent children and single-person households exhibit a relatively smooth trend with a lower rate. This implies that the rise in the overall benefit receipt shown in Figure 1 is primarily driven by the households with dependent children. On the other hand, women and men seem to equally benefit from social assistance and exhibit similar patterns over the observation period, as seen in Figure 3. This is plausible, given that the recipient units are the households, not individuals, as noted by Königs, 2014.

Next, we present the annual transition rates into and out of benefit receipts. We observe an opposite trend in the entry and exit rates over the period, displayed in Figure 4 The pattern is more apparent during the recovery period of the 2008 crisis. That is, a decline in the entry rate is associated with an increase in the exit rate after 2009. The reported transition rates provide evidence about 'raw' state dependence in social assistance receipt - the difference between persistence and entry rate. A high average persistence rate of around 80 percent together with an entry rate of around 5 percent indicates that every three out of four recipients in a given year continue to receive the benefits in the next year. A comparison of benefit transition rates by household type exhibits an unclear pattern. Although 
the interpretation of these patterns shown in Figure 5 is difficult, one can see that the households with dependent children clearly have a higher entry rate and relatively stable exit rate compared to other types of households. It must be noted that the entry rate of single-person households and households without dependent children are lower (around 2 percent by 2011), while they have relatively higher exit rates over the period. The decomposition of entry and exit rates by gender does not display different patterns, as seen in Figure 6. This is consistent with the pattern observed in the benefit receipt rate, by gender (Figure 3).

The raw state dependence observed in Figure 4 may be due to some observed and unobserved characteristics as well as structural features of the social assistance schemes. The main objective of this paper is to analyze to what extent the raw state dependence is structural. In this regard, a regression analysis is conducted in the following section to disentangle the structural state dependence from its spurious components, which arise from the observed and unobserved characteristics.

\section{Empirical Method}

A dynamic random-effects probit model, which is generally being cited in the recent empirical work, is employed to analyze state dependence in social assistance benefit (e.g., Andren and Andren, 2013; Cappellari and Jenkins, 2014 Hansen et al., 2014; Königs, 2014). The model has also been applied to other binary outcomes such as poverty, labor force participation and unemployment (e.g., Arulampalam and Stewart, 2009: Biewen, 2009, Chay and Hyslop, 2014; Stewart, 2007). Unlike these studies, we employ several extensions of Wooldridge s (2005) estimator proposed by Rabe-Hesketh and Skrondal, 2013 to deal with the potential bias in the initial conditions due to the short panel length. We compare these results with those from Heckman's (1981) reduced form approach for different subsets of instruments. This section introduces the models and their extensions mainly on the basis of these cited studies.

The latent equation for the binary outcome variable of being in receipt 
of social assistance is specified as:

$$
\begin{aligned}
y_{i t} & =1\left\{y_{i t}^{*}>0\right\} \\
& =1\left\{\beta_{0}+\beta_{1} y_{i t-1}+X_{i t}^{\prime} \Omega+\alpha_{i}+u_{i t}>0\right\} \quad \text { for }(\mathrm{i}=1, \ldots, \mathrm{N} ; \mathrm{t}=2, \ldots, \mathrm{T})
\end{aligned}
$$

where $y_{i t}$ is the observed binary outcome variable indicating whether the individual is in benefit receipt. $\mathbf{1}($.$) is an indicator function equal to one$ if the latent variable $y_{i t}^{*}>0$, and zero otherwise. In other words, each individual $i$ is observed to be in receipt in year $t$ if the indicator function is equal to one, and to be not in receipt if it is zero. The latent variable, to be interpreted as the potential utility from receiving social assistance, depends on the lagged dependent variable $\left(y_{i t-1}\right)$, observable characteristics $\left(X_{i t}\right)$, unobserved individual-specific random effects $\left(\alpha_{i}\right)$ and a white-noise error term $\left(u_{i t}\right)$. The vector $X_{i t}$ includes variables for gender, age, age square, completed years of education of the reference person as well as of the spouse, number of children, household size, health and employment status.

The white-noise error term is assumed to be serially uncorrelated, independent of $X_{i t}$ and $y_{i t-1}$, and normally distributed. Even if the errors $u_{i t}$ are assumed serially uncorrelated, the composite error term, $v_{i t}=\alpha_{i}+u_{i t}$, would be correlated over time due to the individual-specific time-invariant $\alpha_{i}$ terms. The correlation between the composite error terms from any two different periods $t$ and $s$ is assumed to be the same: $\rho=\operatorname{Corr}\left(v_{i s} . v_{i t}\right)=\sigma_{\alpha}^{2} /\left(\sigma_{\alpha}^{2}+1\right)$ for $t, s=2, \ldots, T ; t \neq s$ and $\sigma_{u}^{2}=1$. It is further assumed that the two error components, $v_{i t}$ and $u_{i t}$, have zero means and are uncorrelated with each other, the dynamic structure of benefit receipt is approximated by a first-order Markov model, and the covariates $\left(X_{i t}\right)$ are strictly exogenous.

Under these conditions, the probability that the individual $i$ receives social assistance at time $t(\mathrm{t}>1)$, conditional on $y_{i t-1}, X_{i t}$ and $\alpha_{i}$, is given by:

$$
\operatorname{Pr}\left(y_{i t}=1 \mid y_{i t-1}, X_{i t}, \alpha_{i}\right)=\Phi\left(\beta_{0}+\beta_{1} y_{i t-1}+X_{i t}^{\prime} \Omega+\alpha_{i}\right)
$$

where $\Phi($.$) is the standard normal cumulative distribution function.$

The standard (uncorrelated) random effects model assumes $\alpha_{i}$ to be uncorrelated with $X_{i t}$. Alternatively, the Mundlak-Chamberlain approach was employed, which allows for correlation between the unobserved individualspecific effect $\alpha_{i}$ and the observed characteristics $X_{i t}$ in the model. This 
correlation is achieved by supposing a relationship between $\alpha_{i}$ and either time-averaged characteristics, also known as Mundlak-averages, or a combination of the variables' lags and leads. Several of the aforementioned studies, such as Cappellari and Jenkins (2008) and Königs (2014), use time-averages $\left(\bar{X}_{i}\right)$, describing $\alpha_{i}=\bar{X}_{i}^{\prime} a+\zeta_{i}$ where $\zeta_{i} \sim N\left(0, \sigma_{\zeta}^{2}\right)$. The individual characteristics that are left in $\zeta_{i}$ are supposed to be independent of $X_{i t}$ and $u_{i t}$ for all $i, t$.

The coefficient estimate of the lagged dependent variable $\beta_{1}$ is interpreted as structural, also known as genuine state dependence in a model specification that controls for both observed and unobserved heterogeneity. Structural state dependence must be distinguished from spurious state dependence. These spurious components are induced by permanent unobserved characteristics, such as unobserved labor market ability or individualistic preferences for benefit receipt, which might lead to a spuriously high level of state dependence (Königs, 2014). The unobserved characteristics are captured by the individual heterogeneity $\left(\alpha_{i}\right)$. The implementation of control for the observed and unobserved heterogeneity eliminates the spurious components and provides with structural state dependence. The study intends to estimate this feature of state dependence.

Estimation of the structural state dependence requires an additional assumption about the initial conditions. It implies the need to specify the relationship between the individual specific effect $\alpha_{i}$ and the dependent variable in the initial period $y_{i 1}$ that typically cannot be treated as exogenous. Unless the start of the process coincides with the start of the observation period for each individual — and this is not the case - there exists a correlation between $\alpha_{i}$ and $y_{i 1}$. This would induce the lagged dependent variable correlated with the composite error term, leading to a bias in parameter estimates. In particular, the estimator of standard random effects probit model that assumes the absence of correlation between the initial conditions and the $\alpha_{i}$ will be inconsistent, which also leads to the overestimation of $\beta_{1}$ in Equation (1), and hence the level of state dependence (Stewart, 2007).

We deal with the initial conditions bias using the Wooldridge (2005) estimator and its extensions proposed by Rabe-Hesketh and Skrondal (2013) in order to avoid the potential bias due to the short panel length. Although the main estimator of our analysis comes from Wooldridge (2005), we also employ the Heckman (1981) estimator to check for the sensitivity of the results. 
Heckman's estimator is introduced prior to the discussion of Wooldridge's estimator and its extensions to simplify understanding regarding the empirical discussion.

\subsection{Heckman's Estimator}

Heckman (1981) specifies a linearized approximation to the reduced form equation for the initial value of the latent variable. Specifically, the latent variable in the initial year $y_{i 1}^{*}$ can be written as:

$$
y_{i 1}^{*}=\pi_{0}+Z_{i 1}^{\prime} \pi_{1}+\theta_{1} \alpha_{i}+u_{i 1} \quad(i=1, \ldots N)
$$

where $Z_{i 1}$ represents a vector of exogenous covariates including explanatory variables observed in the first wave $\left(X_{i 1}\right)$ and pre-sample variables that are deemed as instruments. These pre-sample variables, to be considered as a proxy for poverty, include the ability to afford the bills, rent and credit card payments, and unemployment status over the past year, prior to the initial sample period.

The study assumes the composite error term, $v_{i 1}=\theta \alpha_{i}+u_{i 1}$, to be correlated with $\alpha_{i}$, but uncorrelated with $u_{i t}$ for $t \geq 2^{8}$ The standard assumptions regarding the distributions of the $u_{i t}$ and $\alpha_{i}$ that they are normally distributed, the former with variance 1 , the latter with variance $\sigma_{\alpha}^{2}$ are considered, as before. Given these normalizations, the model can be estimated with maximum likelihood techniques (Stewart, 2007).

Equation (1) and (3) together specify a complete model for $\left(y_{1}, \ldots, y_{T}\right)$. In this model, the contribution to the likelihood function for individual $i$ is given by

$\left.L_{i}=\int\left\{\Phi\left[\left(Z_{i 1}^{\prime} \pi_{1}+\theta_{1} \alpha\right)\left(2 y_{i 1}-1\right)\right] \prod_{t=2}^{T_{i}} \Phi\left[\beta_{1} y_{i t-1}+X_{i t}^{\prime} \Omega_{1}+\theta_{t} \alpha\right)\left(2 y_{i t}-1\right)\right]\right\} g(\alpha) d \alpha$

where $\theta_{T}=1$ for identification ( of $\sigma_{\alpha}^{2}$ ), $g(\alpha)$ is the probability density function of the unobserved individual-specific effect, and $\Phi$ is the standard normal cumulative distribution function. The covariates are considered the same as described above. Longitudinal averages of time-varying variables $\bar{X}_{i}$ (i.e.,

\footnotetext{
${ }^{8}$ A test of $\theta=0$ provides a test of exogeneity of the initial condition in this model.

${ }^{9}$ To simplify notation, the intercepts $\beta_{0}$ and $\pi_{0}$ in Equations (1) and (3) are not explicitly shown in the likelihood function.
} 
health and employment status, number of children, household size) are also included in the regression analysis to allow the correlation between the observed characteristics and unobserved individual heterogeneity. For sake of brevity, $\bar{X}_{i}$ is subsumed in $X_{i t}$. As in the common practice, the integral is evaluated using Gaussian-Hermite quadrature based on the assumption that $\alpha$ is normally distributed (Arulampalam and Stewart, 2009).

\subsection{Wooldridge's Estimator}

Wooldridge (2005) proposes an alternative Conditional Maximum Likelihood estimator that considers the density of $\left(y_{2}, \ldots, y_{T}\right)$ conditional on the initial period value $y_{i 1}$ and exogenous variables, rather than finding the density of $\left(y_{i 1}, \ldots, y_{i T}\right)$ given exogenous explanatory variables. In particular, Wooldridge (2005) specifies an approximation for the density of $\alpha_{i}$ conditional on the initial observation $y_{i 1}$, and either the set of explanatory variables $X_{i}=\left(X_{i 2}, \ldots, X_{i T}\right)$ or averages of the $X$-variables over $t$ as additional regressors in the model.

Wooldridge's estimator has practical advantages over Heckman's estimator that the initial dependent variable does not need to be jointly modeled with the subsequent dependent variables and that estimation can be achieved using standard random effects probit software. However, the parameter estimates from the Wooldridge estimator could be biased in applications that rely on panel data containing a small number of time periods. Akay (2012) suggests the employment of Heckman's estimator instead of Wooldridge's estimator in the case of short-panels for ruling out the bias in the estimates. On the other hand, Rabe-Hesketh and Skrondal (2013) indicate that the auxiliary model for the individual-specific effect used by Akay (2012) is overly-constrained because it includes longitudinal averages across all periods, including the initial period. The bias for the constrained model would disappear when the initial-period explanatory variables are included in the auxiliary model as additional regressors 10 (besides the longitudinal averages as well as the lagged dependent variable). Rabe-Hesketh and Skrondal (2013) also reveal that the Wooldridge's original auxiliary model, in

\footnotetext{
${ }^{10}$ Rabe-Hesketh and Skrondal (2013) show that the problem with the overly-constrained model is that the conditional distribution of the unobserved effect depends more directly on the initial-period explanatory variables than on the explanatory variables at the other periods. The coefficients of the initial-period explanatory variables should therefore not be constrained to equal the coefficients at the other periods.
} 
which the individual-specific effect is conditioned on the lagged dependent variable and explanatory variables at periods $t=2, \ldots, T$, serves as a favorable outcome. We therefore exclude the initial-period characteristics from the covariates and from their longitudinal averages, but include them only as additional regressors in our last specification, in Equation (6).

We begin the analysis with the Wooldridge's 'original model', excluding the initial period regressors, in stead of using the 'overly-constrained model' that includes explanatory variables across all periods. In this specification, we assume the following auxiliary model:

$$
\alpha_{i}=\varsigma_{0}+\varsigma_{1} y_{i 1}+X_{i}^{\prime} \varsigma_{2}+a_{i}
$$

where $X_{i}^{\prime}=\left(X_{i 2}^{\prime}, \ldots, X_{i T}^{\prime}\right)$. The correlation between $y_{i 1}$ and $\alpha_{i}$ is handled by the use of Equation (4), providing another unobservable individual-specific heterogeneity term $a_{i}$ that is uncorrelated with the initial observation $y_{i 1}$. Here and henceforth $a_{i}$ is assumed to be normally distributed with mean 0 and variance $\sigma_{a}^{2}$, given the covariates in each specification.

Secondly, we employ a specification for the individual specific effect following the Mundlak-Chamberlain approach described above:

$$
\alpha_{i}=\varsigma_{0}+\varsigma_{1} y_{i 1}+\bar{X}_{i}^{\prime} \varsigma_{2}+a_{i}
$$

where $\bar{X}_{i}=\frac{1}{T-1} \sum_{t=2}^{T} X_{i t}$ includes time varying explanatory variables that are correlated with the unobservable $\alpha_{i}$.

In the last specification, we add the initial-period explanatory variables $\left(X_{i 1}\right)$ to the auxiliary model as suggested by Rabe-Hesketh and Skrondal (2013). The new specification for the individual-specific effect $\alpha_{i}$ can be written as:

$$
\alpha_{i}=\varsigma_{0}+\varsigma_{1} y_{i 1}+\bar{X}_{i}^{\prime} \varsigma_{2}+X_{i 1}^{\prime} \varsigma_{3}+a_{i}
$$

where $X_{i 1}$ is a vector of explanatory variables in the initial year, and all other variables are as considered in Equation (5).

The probability of benefit receipt is achieved by substituting each of these three auxiliary models into Equation (2), separately. To illustrate, as for the specification (5) the probability of benefit receipt becomes:

$$
\operatorname{Pr}\left(y_{i t}=1 \mid a_{i}, y_{i 1}\right)=\Phi\left[\beta_{0}+\beta_{1} y_{i t-1}+\varsigma_{1} y_{i 1}+\bar{X}_{i}^{\prime} \varsigma_{2}+X_{i t}^{\prime} \Omega+a_{i}\right], \quad(t=2, \ldots, T)
$$


where the constant term $\varsigma_{0}$ is subsumed into $\beta_{0}$. In this model, the contribution to the likelihood function for individual $i$ is given by:

$$
L_{i}=\int\left\{\prod_{t=2}^{T} \Phi\left[\left(\beta_{0}+\beta_{1} y_{i t-1}+\varsigma_{1} y_{i 1}+\bar{X}_{i}^{\prime} \varsigma_{2}+X_{i t}^{\prime} \Omega+a\right)\left(2 y_{i t}-1\right)\right]\right\} g(a) d a
$$

where $g(a)$ is the normal probability density function of the new unobserved individual-specific effect $a_{i}$, specified in Equation (5). The likelihood function is maximized evaluating the integral over $a$, using Gaussian-Hermite quadrature, which is based on the assumption that $a$ is normally distributed.

\section{Results}

This section presents estimation results from the specifications explained earlier. Given the non-linearity of the models, the magnitudes of the coefficient estimates provide little information about the size of the effects of the observable characteristics, and hence the degree of state dependence. The level of state dependence is assessed through the measure of average partial effect of benefit receipt. The next subsection elaborates on this issue.

As previously mentioned, the main estimator of this analysis is the Wooldridge estimator. The development of this estimator was based on a balanced sample. Given the concern that sample drop out is not random, the unobservable determinants of non-response or panel attrition are correlated with the unobservables determining benefit receipt. Considering this concern, we mainly rely on a balanced sample analysis in which only individuals tracked over the entire panel period are kept in the operational sample. We also report estimates using unbalanced panel for sake of comparison. In fact, many of the previous studies use balanced panel to avoid the potential attrition bias 11 Only a few studies such as of Cappellari and Jenkins (2014) and Königs (2014) rely on an unbalanced sample mainly due to a huge drop in the number of observations in balanced pane ${ }^{12}$. However, this is not a worrying issue for the analysis because a relatively shorter panel is employed for the study. Hence, the sample size remains sufficiently large in the bal-

\footnotetext{
${ }^{11}$ See Andren and Andren 2013 Biewen 2009, Hansen et al. 2014 Stewart 2007.

${ }^{12}$ Königs (2014) deals with the attrition bias problem constructing a weakly balanced panel, while Cappellari and Jenkins (2014) rely on the finding that the impact of attrition is small in their sample, previously reported by Cappellari and Jenkins (2008).
} 
anced panel. Hereby, the results from the Wooldridge estimator based on a balanced sample are discussed prior to comparing them with the results from the Heckman estimator. The results from both estimators, based on an unbalanced sample, are presented in Appendix Table B.1 and Table B.2. The noticeably higher coefficient estimates (as well as higher average partial effect) from the unbalanced sample can be interpreted as evidence of the attrition bias leading to an overestimate of state dependence. Therefore, the study limits the discussion to estimates using balanced sample.

Estimation results of the dynamic random effects probit model based on the Wooldridge estimator are presented in Table 1 . The first column provides estimates assuming that initial conditions are exogenous, and columns 2 to 4 display the results obtained from the extensions specified in Equations (4), (5) and (6), respectively. The coefficient estimate of the lagged recipient status, namely state dependence, lie in the narrow range between 1.38 and 1.31 , and all are strongly statistically significant. This range is according to the three specifications that allow for endogenous initial conditions (columns 2-4, row 1). The magnitude of the coefficient estimate decreases as the within-means (of time varying) and the initial-period explanatory variables are added to the regression (as going from column 2 to column 4).

On the other hand, the failure to account for endogenous initial conditions doubles the coefficient estimate of the lagged dependent variable (column 1, row 1 ). The reduction in the coefficient estimate after controlling for endogenous initial conditions coincides with an increase in the estimated standard deviation of the individual-specific effect $\left(\sigma_{\alpha}\right)$, which is reported at the bottom of the table. $\sigma_{\alpha}$ is estimated as about 1 , which translates into a cross-period correlation $(\rho)$ in the composite error term of around 0.5. This implies that half of the variance in the composite error term comes from the permanent individual unobserved heterogeneity. The coefficient estimate of the control for the receipt status in the initial period $(t=1)$ is positive and statistically significant. This points out that individuals who have received social assistance benefit in the previous period have a higher probability for receiving benefit in following periods. Taken together, our results support the evidence that the estimates based on the exogeneity assumption suffer from initial conditions bias, and this bias has the potential to overestimate the degree of state dependence ${ }^{13}$

\footnotetext{
${ }^{13}$ Furthermore, the hypothesis $\theta=0$, exogeneity of the initial condition, is strongly
} 
Columns 2 to 4 of Table 1 represent the extensions of the Wooldridge's approach, taking into account for the potential bias in the estimates due to a shorter time span of panel, discussed in Section 5. It is clearly safer to err on the side of caution and therefore the current study also discusses the results from the Heckman's approach as suggested by Akay (2012). Table 2 shows the estimation results for two different specifications of the Heckman's approach, using different subsets of instruments to estimate the initial conditions equation (Equation (3)). The results from the first specification using the first-wave characteristics as instruments are presented in column 1, and the corresponding estimates from its initial conditions equation are shown in column 2. The right panel of the table display the results from the second specification, exploiting pre-sample characteristics in addition to the firstwave characteristics for estimation of the initial condition equation. The pre-sample characteristics involving the information about the past unemployment status (one year prior to the first wave), and past ability to afford bills, rent and credit card payments are presented at the bottom of Table 2 , respectively. The coefficient estimate of the lagged dependent variable, fluctuating around 1.45, is slightly higher than the results obtained from the Wooldridge estimator. The magnitude of the coefficient estimate is not sensitive to the choice of instrument, changing the coefficients only in small margins. The consistency in the estimation results across the specifications, particularly between the Wooldridge's and Heckman's approaches, avoids our concerns about the bias in the Wooldridge estimates due to using a short pane ${ }^{14}$.

The specifications consist of covariates including individual characteristics (sex, age, age square, marital status, education tenure, spouse's education, health and employment status), household characteristics (number of children, household size) and year dummies. The relations between the individual- and household- characteristics and the likelihood of being in receipt are generally in the expected direction. The signs of the estimates of the explanatory variables derived from the Wooldridge estimator do not differ than those from the Heckman estimator. The probability of receiving

rejected in the Heckman's reduced form model, in Equation (3). Rather the estimate of $\theta$ is close to, and insignificantly different from 1, as reported in Table 2

${ }^{14}$ The lower coefficient estimates (and average partial effect) from the Wooldridge's specifications relative to those from Heckman's estimator indicate that the Wooldridge estimates are unlikely to suffer from an upward bias. 
social assistance benefit decreases with an increase in age, though the estimate is either at the borderline significance or insignificant. As one would expect, both the respondent's and the spouse's educational attainment are negatively and strongly associated with benefit receipt. On the other hand, having a restrictive health condition and being unemployed make people more likely to receive benefit. Surprisingly, the gender does not seem to be related with the benefit receipt. This finding is, however, consistent with very similar trends in benefit receipts and transition rates for women and men, illustrated in Figure 3 and Figure 6 . As stated by Königs (2014), this could be explained by the definition of the beneficiary unit, whereupon our analysis relies on. Women and men who live in the same household are treated equally as recipients, since we have defined benefit receipt at household level.

The household characteristics, such as the number of dependent children and household size are not strongly associated with benefit receipt, which could be related with the insufficient time variation in those variables over the period. The time-averages of these variables, particularly the coefficient estimate of the number of children, are rather statistically significant Table 1 and Table 2]. Child allowances account for a considerable share among the social assistance schemes, and therefore a household having dependent children increases its likelihood of being in receipt Figure 2). Overall, the time-averages play an important role in the models. In particular, they help to control for the potential correlation between the unobserved individual heterogeneity and the observed characteristics. Most of the coefficients on the time-averaged variables are statistically significant, and their signs are the same as the corresponding variables. The model also captures time trends in benefit receipt during the observation period, using year dummy variables as covariates. The study finds positive and statistically significant coefficient estimates for the 2008-2011 period. This is consistent with the increasing rate of benefit receipt over most of the sample period, shown in Figure 1.

\subsection{Degree of State Dependence}

Estimation results from the dynamic random effects probit model presented in Table 1 and Table 2 suggest considerable state dependence in social assistance benefit receipt in Turkey. The coefficient estimates of the lagged 
benefit receipt is always positive and statistically significant regardless of the specification relied on. Lastly, we discuss the average partial effect of benefit receipt to assess the level of state dependence. The average partial effect simply equals to the difference in average predicted probabilities of social assistance receipt across individuals over time conditional on benefit receipt and non-receipt in the previous period (i.e., the difference between predicted persistence and entry probabilities) (Stewart, 2007).

The estimated transition rates (of entry and exit) and average partial effects are presented at the bottom panel of each table. In the case of the Wooldridge's original specification (Equation (4)), the estimates in column 2 of Table 1 indicate an average probability of benefit receipt at $t$ conditional on receipt at $t-1$ of 21.4 percent (persistence rate), and the average probability of benefit receipt at $t$ conditional on non-receipt at $t-1$ is 1.5 percent (entry rate). The average partial effect is thus 19.9 percentage points, which decreases to 18.1 percentage points when the study relies on the second specification. The second specification in Equation (5) facilitates addition of within-means of time varying explanatory variables to the regression. The inclusion of additional control variables of first-wave characteristics, as in the case of Equation (6), lowered the average partial effect by 17 percentage points. The average partial effect exceeds 30 percentage points among unemployed people with educational attainment lower than secondary school and those with two or more children. These results, though not presented in the table, are consistent with the explanatory power of the covariates.

On the other hand, the average partial effects calculated based on the Heckman estimator, of about 22 percentage points, are higher than the results from the Wooldridge estimator. This is consistent with the relatively higher coefficient estimates of the lagged dependent variable from the Heckman estimator, reported in Table 2. While the structural state dependence of around 17 to 22 percentage point is substantial, the value is considerably lower than the difference between the observed persistence and entry rates of about 75 percent, illustrated in Figure 4 . This implies that most of the observed state dependence is due to the observed and unobserved heterogeneity across individuals (Hansen et al. (2014); Königs (2014)).

The average partial effects estimated for Turkey are at least 3 percentage points higher than those reported by Cappellari and Jenkins (2008) for the United Kingdom (of 14.4 percentage points) and by Königs (2014) for Ger- 
many (of 14.1 percentage points). While the estimated persistence rate is comparable to these countries, the entry rate is around 4 percentage points lower in Turkey. These results suggest that state dependence in social assistance might also be a relevant phenomenon for developing countries. Contrary to the developed countries, the generosity of the welfare system cannot be considered as a responsible for the high level of state dependence in Turkey. The situation in Turkey rather addresses the poorly-designed social assistance schemes and dysfunction in monitoring mechanisms (see Appendix A). The strong evidence of structural state dependence leaves a large room for policy implications in reducing the high persistence rate in benefit receipt. The policies could attempt either to promote exits from benefits, and hence to reduce the persistence rate, or to allow for new entries in the system. The latter is at least as important as reducing the persistence rate for developing countries that suffer from high level of poverty, given the key role of social assistance in poverty alleviation.

\section{Conclusion}

The empirical evidence on the evaluation of dynamics of social assistance benefits has thus far been limited to the developed economies, despite the existence of social transfers in many developing countries. The current study examined this issue in Turkey, over the last decade, within the state dependence framework. This is the first empirical study to explore state dependence in social assistance benefit receipt, in context of a developing country.

Based on annual panel data for the 2006-2012 period, dynamic random effects probit model was employed for controlling unobserved heterogeneity and initial conditions. Given the short length of the chosen panel, three extensions of Wooldridge's estimator proposed by Rabe-Hesketh and Skrondal (2013) were introduced in the study. In order to model initial conditions and check for sensitivity, the results from Heckman's two step estimator were compared with the results from Wooldridge's estimator. The methodological contribution of the study highlights the feasibility of a state dependence analysis using a short panel, which is of particular importance for developing countries, where it is difficult to find and employ long-panel datasets. The results are quite consistent across different specifications and suggest strong evidence of state dependence in social assistance benefit receipt. It was found 
that social assistance benefit receipt in previous year increases the probability of being in receipt in current year by 17 to 22 percentage points, after controlling unobserved characteristics and endogenous initial conditions.

Although Turkey is far from having a generous welfare benefit system, the level of state dependence is higher than that reported for Germany, the United Kingdom and Canada. This evidence suggests that state dependence in social assistance might also be a relevant phenomenon for developing countries. These findings give rise to several interesting questions: Do the social assistance schemes in Turkey suffer from inefficiencies that lead to a relatively high structural state dependence? If yes, what kind of improvements in the welfare system are required to overcome this problem? Lack of a well-defined poverty-scoring formula and a nationwide standard eligibility criteria leave a large room for discretionary implementations and political preferences, particularly in allocating the benefits by local authorities. Unfortunately, due to the data limitation it was unlikely to assess the impact of political preferences on benefit receipt. However, one can suggest that more transparent and clear eligibility criteria along with better enforcement and monitoring mechanisms might reduce the current level of state dependence, thereby bringing about a more efficient welfare system. On the other hand, activation programs and work incentives are highly debated policy reforms in developed countries. In view of this context, such policies could facilitate a higher mobility allowing for new entries in the system, and hence prove to be a relevant policy implication.

\section{References}

Adaman, F., A. Carkoglu, R. Erzan, A. Filiztekin, B. Ozkaynak, S. Sayan, and S. Ulgen. The social dimension in selected candidate countries in the Balkans: Country report on Turkey. 2007.

Ahmed, A., M. Adato, A. Kudat, D. Gilligan, and R. Colasan. Impact evaluation of the conditional cash transfer program in Turkey: Final report. International Food Policy Research Institute, Washington, DC, 2007.

Akay, A. Finite-sample comparison of alternative methods for estimating dynamic panel data models. Journal of Applied Econometrics, 27(7):1189-1204, 2012.

Andren, T. and D. Andren. Never give up? The persistence of welfare participation in Sweden. IZA Journal of European Labor Studies, 2(1), 2013.

Arulampalam, W. and M. B. Stewart. Simplified implementation of the Heckman estima- 
tor of the dynamic probit model and a comparison with alternative estimators. Oxford bulletin of economics and statistics, 71(5):659-681, 2009.

Aytaç, S. E. Distributive politics in a multiparty system the conditional cash transfer program in Turkey. Comparative Political Studies, 47(9):1211-1237, 2014.

Baird, S., C. McIntosh, and B. Özler. Cash or condition? Evidence from a cash transfer experiment. The Quarterly Journal of Economics, pages 1-32, 2011.

Biewen, M. Measuring state dependence in individual poverty histories when there is feedback to employment status and household composition. Journal of Applied Econometrics, 24(7):1095-1116, 2009.

Buğra, A. Capitalism, poverty and social policy in Turkey (in Türkish). Iletisim Press, 2009.

Cappellari, L. and S. P. Jenkins. The dynamics of social assistance receipt: Measurement and modelling issues, with an application to Britain. 2008.

Cappellari, L. and S. P. Jenkins. The dynamics of social assistance benefit receipt in Britain. Research in Labor Economics, 39:39-77, 2014.

Chay, K. Y. and D. Hyslop. Identification and estimation of dynamic binary response panel data models: Empirical evidence using alternative approaches. Research in Labor Economics:" Safety Nets and Benefit Dependence, 39:1-39, 2014.

Duflo, E. Grandmothers and granddaughters: Old-age pensions and intrahousehold allocation in South Africa. The World Bank Economic Review, 17(1):1-25, 2003.

Edmonds, E. and N. Schady. Poverty alleviation and child labor. American Economic Journal: Economic Policy, 4(4):100-124, 2012.

Hansen, J., M. Lofstrom, X. Liu, and X. Zhang. State dependence in social assistance receipt in Canada. Research in Labor Economics:" Safety Nets and Benefit Dependence, 39:81-105, 2014.

Heckman, J. J. The incidental parameters problem and the problem of initial conditions in estimating a discrete time-discrete data stochastic process. 1981.

Karagöl, E. T., J. Yildirim, A. Murat, A. Eralp, F. Güneş, and M. Sungur. The determining factors of social assistance benefit recipirients in Turkey (in Türkish). İktisadi ve İdari Bilimler Fakültesi Dergisi, 15(1):1-22, 2013.

Königs, S. The dynamics of social assistance benefit receipt in Germany - State dependence before and after the Hartz reforms. 2014.

Law. Law of encouraging social assistance and solidarity (in Türkish). Official Gazette numbered 19134, dated 14/6/1986, 3294.

Manacorda, M., E. Miguel, and A. Vigorito. Government transfers and political support. Technical report, National Bureau of Economic Research, 2009.

Metin, O. The AKP period from the social policy perspective: Developments in the field of social assistance (in Türkish). Çalısma ve Toplum, 1:179-200, 2011. 
Rabe-Hesketh, S. and A. Skrondal. Avoiding biased versions of Wooldridge's simple solution to the initial conditions problem. Economics Letters, 120(2):346-349, 2013.

Scholz, J. K., R. Moffitt, and B. Cowan. Trends in income support. Changing poverty, changing policies, pages 203-41, 2009.

Şeker, S. D. The effects of social transfers on poverty in Turkey (in Türkish). Devlet Planlama Teşkilatı, 2008.

Stewart, M. B. The interrelated dynamics of unemployment and low-wage employment. Journal of applied econometrics, 22(3):511-531, 2007.

Wooldridge, J. M. Simple solutions to the initial conditions problem in dynamic, nonlinear panel data models with unobserved heterogeneity. Journal of applied econometrics, 20 (1):39-54, 2005. 


\section{Figures and Tables}

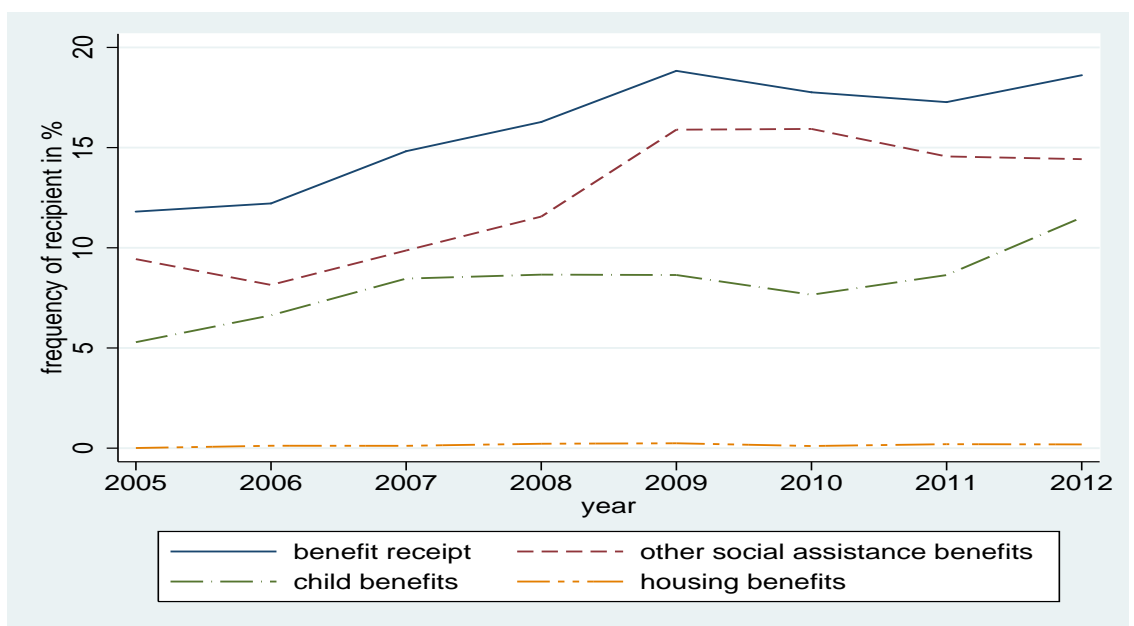

Figure 1: Rate of benefit receipt of all individuals

Note: Benefit receipt rate refers to the share of working age individuals from a benefit receiving household. It is calculated using individual sampling weights based on micro data from SILC.

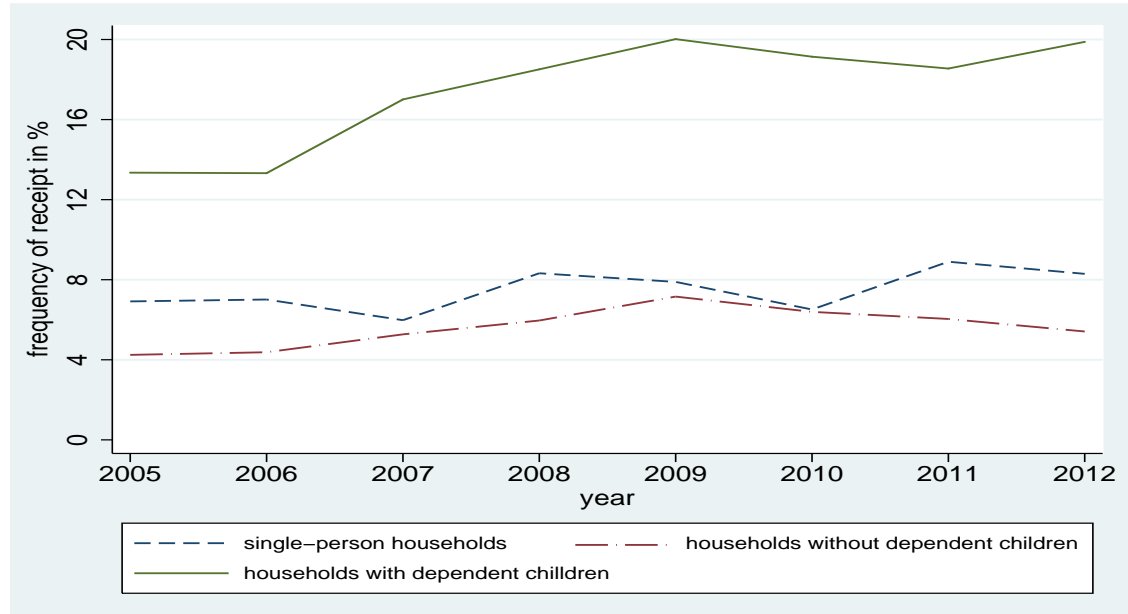

Figure 2: Rates of benefit receipt by household type

Note: Benefit receipt rate refers to the share of benefit receiving households of the given type. It is calculated using household sampling weights based on micro data from SILC. 


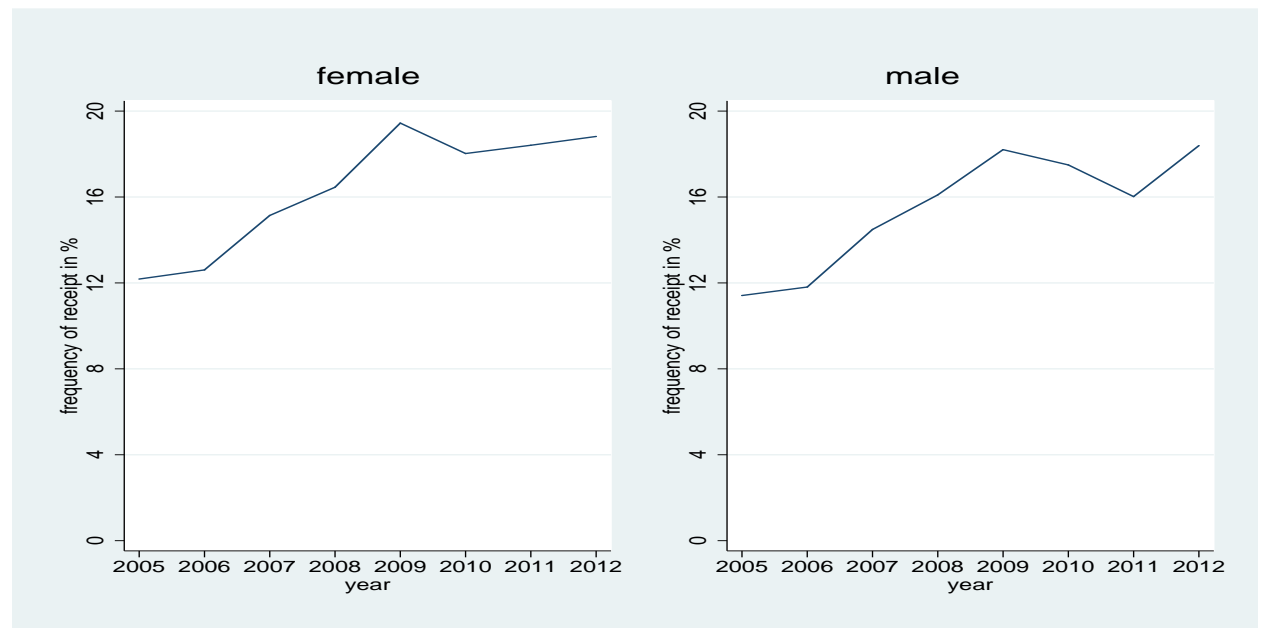

Figure 3: Rates of benefit receipt by gender

Note: Benefit receipt rate refers to the share of working age females (males) who are a member of a benefit receiving household. It is calculated using individual sampling weights based on micro data from SILC.
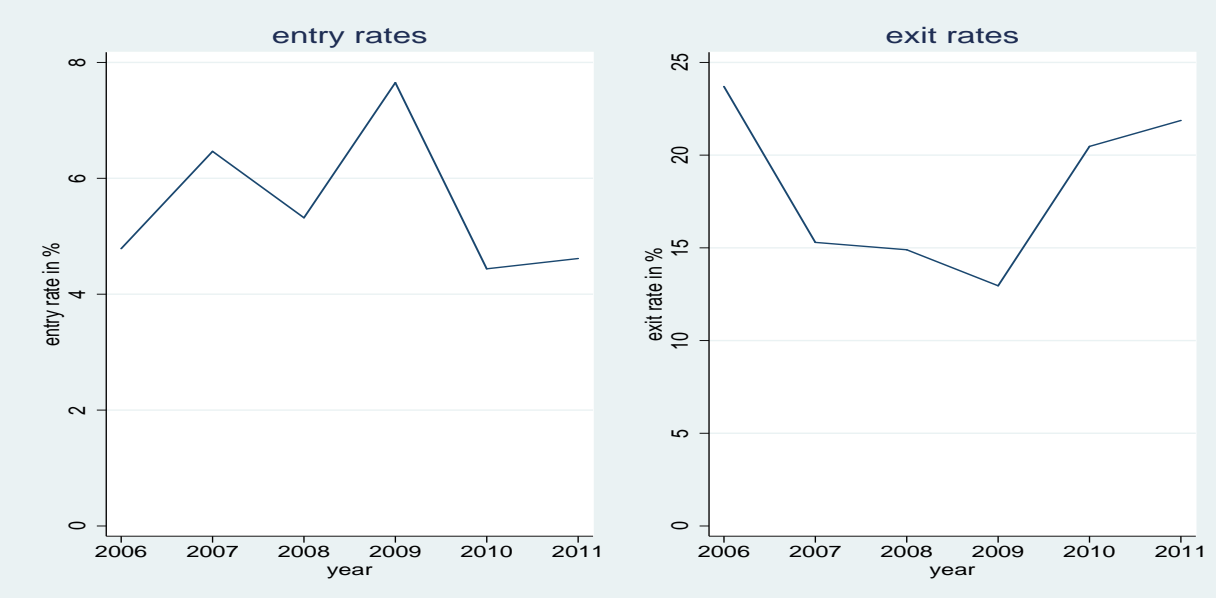

Figure 4: Benefit transition rates of all individuals

Note: Entry rate is defined as the number of recipients at time $t$ among those who were not in receipt at time $t-1$ divided by the total number of individuals not in receipt at $t-1$. Exit rate is the number of non-recipients at $t$ among those who were in receipt at time $t-1$ divided by the total number of individuals in receipt at $t-1$. Persistence rate is equal to one minus the exit rate. All rates are expressed as a percentage and are calculated using individual sampling weights based on micro data from SILC. 

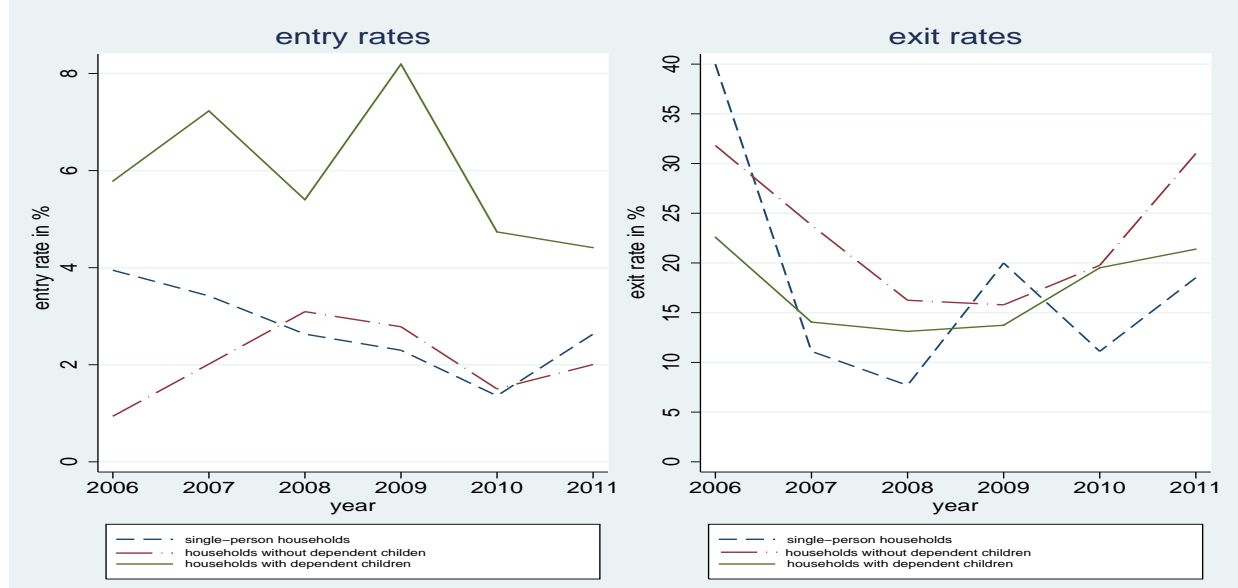

Figure 5: Benefit transition rates by household type

Note: Entry rate is defined as the number of recipient households at time $t$ among those who were not in receipt at time $t-1$ divided by the total number of households not in receipt at $t-1$. Exit rate is the number of non-recipient households at $t$ among those who were in receipt at time $t-1$ divided by the total number of households in receipt at $t-1$. Persistence rate is equal to one minus the exit rate. All rates are expressed as a percentage and are calculated using household sampling weights based on micro data from SILC.
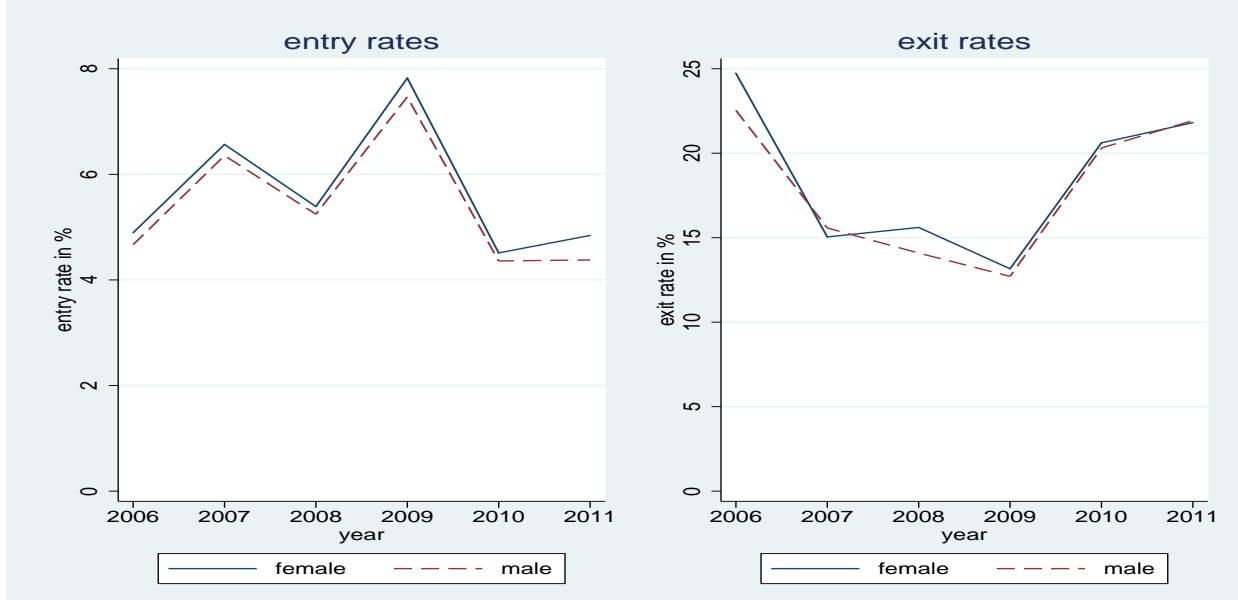

Figure 6: Benefit transition rates by gender

Note: Entry rate is defined as the number of females (males) in benefit receipt at time $t$ among those who were not in receipt at time $t-1$ divided by the total number of individuals not in receipt at $t-1$. Exit rate is the number of non-recipient females (males) at time $t$ among those who were in receipt at time $t-1$ divided by the total number of individuals in receipt at $t-1$. Persistence rate is equal to one minus the exit rate. All rates expressed as a percentage and are calculated using individual sampling weights based on micro data from SILC. 
Table 1. Dynamic Random Effects Probit Model :

Wooldridge's Estimator

(in a Balanced Sample)

\begin{tabular}{|c|c|c|c|c|}
\hline & $(1)$ & $(2)$ & $(3)$ & $(4)$ \\
\hline Benefit receipt at $t-1$ & $\begin{array}{l}2.301^{* * *} \\
(0.047)\end{array}$ & $\begin{array}{l}1.375^{* * *} \\
(0.112)\end{array}$ & $\begin{array}{l}1.336^{* * *} \\
(0.113)\end{array}$ & $\begin{array}{l}1.310^{* * *} \\
(0.114)\end{array}$ \\
\hline Benefit receipt at $t=1$ & & $\begin{array}{l}1.727 * * * \\
(0.221)\end{array}$ & $\begin{array}{l}1.756^{* * *} \\
(0.221)\end{array}$ & $\begin{array}{l}1.812^{* * *} \\
(0.225)\end{array}$ \\
\hline \multicolumn{5}{|l|}{ Personal characteristics } \\
\hline Age & $\begin{array}{c}-0.036^{*} \\
(0.020)\end{array}$ & $\begin{array}{c}-0.060^{*} \\
(0.034)\end{array}$ & $\begin{array}{c}-0.062^{*} \\
(0.034)\end{array}$ & $\begin{array}{l}0.168 \\
(0.162)\end{array}$ \\
\hline Age square & $\begin{array}{l}0.000 \\
(0.000)\end{array}$ & $\begin{array}{l}0.001 \\
(0.000)\end{array}$ & $\begin{array}{l}0.001 \\
(0.000)\end{array}$ & $\begin{array}{l}-0.002 \\
(0.002)\end{array}$ \\
\hline Female & $\begin{array}{l}0.00766 \\
(0.239)\end{array}$ & $\begin{array}{l}-0.0555 \\
(0.383)\end{array}$ & $\begin{array}{c}-0.0872 \\
(0.390)\end{array}$ & $\begin{array}{l}-0.106 \\
(0.516)\end{array}$ \\
\hline Years of schooling & $\begin{array}{l}-0.056^{* * *} \\
(0.007)\end{array}$ & $\begin{array}{l}-0.089^{* * *} \\
(0.013)\end{array}$ & $\begin{array}{l}-0.089^{* * *} \\
(0.013)\end{array}$ & $\begin{array}{l}-0.047 \\
(0.060)\end{array}$ \\
\hline Spouse's education & $\begin{array}{l}-0.046^{* * *} \\
(0.007)\end{array}$ & $\begin{array}{l}-0.072^{* * *} \\
(0.012)\end{array}$ & $\begin{array}{l}-0.067^{* * *} \\
(0.013)\end{array}$ & $\begin{array}{l}-0.066 \\
(0.051)\end{array}$ \\
\hline No. children & $\begin{array}{l}0.064 \\
(0.083)\end{array}$ & $\begin{array}{l}0.305^{* * *} \\
(0.0448)\end{array}$ & $\begin{array}{l}0.106 \\
(0.101)\end{array}$ & $\begin{array}{l}0.070 \\
(0.104)\end{array}$ \\
\hline Household size & $\begin{array}{l}0.056 \\
(0.070)\end{array}$ & $\begin{array}{l}-0.032 \\
(0.031)\end{array}$ & $\begin{array}{l}0.067 \\
(0.086)\end{array}$ & $\begin{array}{l}0.090 \\
(0.088)\end{array}$ \\
\hline Poor health & $\begin{array}{l}0.095 \\
(0.070)\end{array}$ & $\begin{array}{l}0.230 * * * \\
(0.067)\end{array}$ & $\begin{array}{l}0.131 \\
(0.086)\end{array}$ & $\begin{array}{l}0.142 \\
(0.087)\end{array}$ \\
\hline Unemployed & $\begin{array}{l}-0.129 \\
(0.121)\end{array}$ & $\begin{array}{l}0.187 \\
(0.118)\end{array}$ & $\begin{array}{l}-0.126 \\
(0.146)\end{array}$ & $\begin{array}{l}-0.103 \\
(0.148)\end{array}$ \\
\hline \multicolumn{5}{|l|}{ Time-averages } \\
\hline Avg: no. children & $\begin{array}{l}0.150 * \\
(0.0865)\end{array}$ & & $\begin{array}{l}0.247^{* *} \\
(0.111)\end{array}$ & $\begin{array}{l}0.269 \\
(0.174)\end{array}$ \\
\hline Avg: household size & $\begin{array}{l}-0.097 \\
(0.073)\end{array}$ & & $\begin{array}{l}-0.125 \\
(0.093)\end{array}$ & $\begin{array}{l}-0.189 \\
(0.142)\end{array}$ \\
\hline Avg: poor health & $\begin{array}{l}0.192^{* *} \\
(0.097)\end{array}$ & & $\begin{array}{l}0.267^{*} \\
(0.144)\end{array}$ & $\begin{array}{l}0.341^{*} \\
(0.187)\end{array}$ \\
\hline Avg: unemployed & $\begin{array}{l}0.600 * * * \\
(0.171)\end{array}$ & & $\begin{array}{l}0.927 * * * \\
(0.260)\end{array}$ & $\begin{array}{l}1.029 * * * \\
(0.334)\end{array}$ \\
\hline \multicolumn{5}{|l|}{ First-wave characteristics } \\
\hline Fst: age & & & & $\begin{array}{c}-0.238 \\
(0.163)\end{array}$ \\
\hline Fst: age square & & & & $\begin{array}{l}0.002 \\
(0.00181)\end{array}$ \\
\hline Fst: years of schooling & & & & $\begin{array}{l}-0.043 \\
(0.0603)\end{array}$ \\
\hline
\end{tabular}


Fst: spouse's education

$-0.002$

(0.0517)

Fst: no. children

0.031

(0.139)

Fst: household size

0.032

(0.114)

Fst: poor health

$-0.066$

(0.119)

Fst: unemployed

$-0.132$

(0.205)

Survey year

2008

$0.287^{* * *} \quad 0.418^{* * *}$

$0.414^{* * *}$

$0.364^{* * *}$

2009

(0.073)

(0.090)

(0.092)

(0.082)

0.186 **

$0.419^{* * *}$

$0.409^{* * *}$

$0.328^{* * *}$

(0.077)

(0.095)

(0.099)

(0.108)

2010

$0.346^{* * *}$

$0.488^{* * *}$

$0.501^{* * *}$

$0.501^{* * *}$

(0.073)

(0.103)

(0.105)

(0.106)

2011

0.077

0.256 **

$0.251 * *$

0.210 **

(0.077)

(0.107)

(0.110)

(0.087)

2012

$-0.031$

0.109

0.077

(0.081)

(0.109)

(0.114)

Constant

$-0.554$

$-0.494$

$-0.570$

$-0.509$

$\sigma_{\alpha}$

(0.432)

(0.705)

(0.722)

(0.772)

\begin{tabular}{llll}
0.001 & $0.999^{* * *}$ & $1.034^{* * *}$ & $1.055^{* * *}$ \\
$(0.011)$ & $(0.108)$ & $(0.109)$ & $(0.110)$ \\
0.000 & $0.499^{* * *}$ & $0.516^{* * *}$ & $0.527^{* * *}$ \\
$(0.000)$ & $(0.054)$ & $(0.053)$ & $(0.052)$ \\
-2128.861 & -2088.697 & -2077.703 & -2056.757 \\
10,239 & 10,239 & 10,239 & 10,156 \\
3,450 & 3,450 & 3,450 & 3,400 \\
$70.3 \%$ & $21.4 \%$ & $19.6 \%$ & $18.4 \%$ \\
$3.9 \%$ & $1.5 \%$ & $1.5 \%$ & $1.4 \%$ \\
66.4 & 19.9 & 18.1 & 17.0 \\
\hline
\end{tabular}

Log likelihood

No. observations

Robust standard errors in parentheses. ${ }^{* * *} \mathrm{p}<0.01,{ }^{* *} \mathrm{p}<0.05,{ }^{*} \mathrm{p}<0.1$

\begin{tabular}{lllll} 
No. individuals & 3,450 & 3,450 & 3,450 & 3,400 \\
\hline Persistence rate & $70.3 \%$ & $21.4 \%$ & $19.6 \%$ & $18.4 \%$ \\
Entry rate & $3.9 \%$ & $1.5 \%$ & $1.5 \%$ & $1.4 \%$ \\
Average partial effect & 66.4 & 19.9 & 18.1 & 17.0 \\
\hline \hline \multicolumn{2}{l}{ Robust standard errors in parentheses. ${ }^{* * *} \mathrm{p}<0.01,{ }^{* *} \mathrm{p}<0.05,{ }^{*} \mathrm{p}<0.1$}
\end{tabular}


Table 2 Dynamic Random Effects Probit Model:Heckman's Estimator (in Balanced Sample)

\begin{tabular}{|c|c|c|c|c|}
\hline & (1) & $\begin{array}{l}(2) \\
\text { initial cond. }\end{array}$ & (3) & $\begin{array}{l}(4) \\
\text { initial cond. }\end{array}$ \\
\hline Benefit receipt at $t-1$ & $\begin{array}{l}1.451^{* * * *} \\
(0.0979)\end{array}$ & & $\begin{array}{l}1.472^{* * *} \\
(0.100)\end{array}$ & \\
\hline \multicolumn{5}{|l|}{ Personal characteristics } \\
\hline Age & $\begin{array}{l}-0.039 \\
(0.034)\end{array}$ & & $\begin{array}{l}-0.039 \\
(0.033)\end{array}$ & \\
\hline Age square & $\begin{array}{l}0.000 \\
(0.000)\end{array}$ & & $\begin{array}{l}0.000 \\
(0.000)\end{array}$ & \\
\hline Female & $\begin{array}{l}0.091 \\
(0.484)\end{array}$ & & $\begin{array}{l}0.083 \\
(0.486)\end{array}$ & \\
\hline Years of schooling & $\begin{array}{l}-0.116^{* * *} \\
(0.014)\end{array}$ & & $\begin{array}{l}-0.115^{* * *} \\
(0.014)\end{array}$ & \\
\hline Spouse's education & $\begin{array}{l}-0.086^{* * *} \\
(0.013)\end{array}$ & & $\begin{array}{l}-0.084^{* * *} \\
(0.013)\end{array}$ & \\
\hline No. children & $\begin{array}{l}0.142 \\
(0.095)\end{array}$ & & $\begin{array}{l}0.141 \\
(0.095)\end{array}$ & \\
\hline Household size & $\begin{array}{l}0.029 \\
(0.080)\end{array}$ & & $\begin{array}{l}0.028 \\
(0.079)\end{array}$ & \\
\hline Poor health & $\begin{array}{l}0.119 \\
(0.083)\end{array}$ & & $\begin{array}{l}0.119 \\
(0.083)\end{array}$ & \\
\hline Unemployed & $\begin{array}{l}-0.084 \\
(0.141)\end{array}$ & & $\begin{array}{l}-0.084 \\
(0.141)\end{array}$ & \\
\hline Time-averages & & & & \\
\hline Avg: no. children & $\begin{array}{l}0.328^{* * *} \\
(0.108)\end{array}$ & & $\begin{array}{l}0.320^{* * *} \\
(0.108)\end{array}$ & \\
\hline Avg: household size & $\begin{array}{l}-0.127 \\
(0.087)\end{array}$ & & $\begin{array}{l}-0.124 \\
(0.086)\end{array}$ & \\
\hline Avg: poor health & $\begin{array}{l}0.455^{* * *} \\
(0.140)\end{array}$ & & $\begin{array}{l}0.459 * * * \\
(0.139)\end{array}$ & \\
\hline Avg: unemployed & $\begin{array}{l}1.070 * * * \\
(0.254)\end{array}$ & & $\begin{array}{l}1.066^{* * *} \\
(0.254)\end{array}$ & \\
\hline First-wave characteristics & & & & \\
\hline Fst: age & & $\begin{array}{l}0.007 \\
(0.045)\end{array}$ & & $\begin{array}{l}0.003 \\
(0.046)\end{array}$ \\
\hline Fst: age square & & $\begin{array}{l}-0.000 \\
(0.001)\end{array}$ & & $\begin{array}{l}-0.000 \\
(0.001)\end{array}$ \\
\hline Fst: female & & $\begin{array}{l}0.245 \\
(0.611)\end{array}$ & & $\begin{array}{l}0.168 \\
(0.613)\end{array}$ \\
\hline Fst: years of schooling & & $\begin{array}{l}-0.129^{* * *} \\
(0.016)\end{array}$ & & $\begin{array}{l}-0.127^{* * *} \\
(0.016)\end{array}$ \\
\hline
\end{tabular}


Fst: spouse's education

Fst: no. children

Fst: household size

Fst: poor health

Fst: unemployed

Pre-sample characteristics

Pre: unemployed

Pre: poverty 1

Pre: poverty2

Pre: poverty3

\section{Constant}

Year dummies

\begin{tabular}{lll|ll} 
Year dummies & Yes & Yes & Yes & Yes \\
\hline$\theta$ & 0.047 & & 0.068 & \\
& $(0.129)$ & & $(0.134)$ & \\
$\rho$ & 0.215 & & 0.168 & \\
& $(0.220)$ & & $(0.231)$ & \\
Log likelihood & -3185.863 & & -3174.740 & \\
No. observations & 10,239 & 10,239 & 10,239 & 10,239 \\
\hline Persistence rate & $22.3 \%$ & & $23.4 \%$ & \\
Entry rate & $1.3 \%$ & & $1.4 \%$ & \\
Average partial effect & 21.0 & & 22.0 & \\
\hline \hline
\end{tabular}

Robust standard errors in parentheses. ${ }^{* * *} \mathrm{p}<0.01,{ }^{* *} \mathrm{p}<0.05,{ }^{*} \mathrm{p}<0.1$
$-0.086^{* * *}$

(0.016)

$0.438 * * *$

$(0.061)$

$-0.106^{* *}$

(0.046)

$0.452^{* * *}$

(0.099)

0.486

(0.390)

0.233

(0.417)

0.002

(0.127)

$0.156^{*}$

(0.093)

$0.326^{* * *}$

(0.097)

$-0.845$

(0.942)

$-0.294$

(0.713)

Yes

0.068

0.168

$0.231)$

$-3174.740$

$23.4 \%$

$1.4 \%$ 


\section{Appendix A Institutional Background}

Social assistance schemes in Turkey are mainly coordinated by the central government, local authorities appointed by the central government, or municipalities. The key governmental institution responsible for this coordination is the Social Assistance and Solidarity Fund (SASF). Although SASF has been legally existent for nearly thirty years to assist people in absolute poverty, Turkey in fact lacks in a well-targeted and well-designed social safety net (Ahmed et al. 2007). On the other hand, the country has recently experienced noticeable changes in the field of social assistance. An increase in the number of beneficiaries and in the share of government budgets allocated to social assistance schemes, indicated in Section 1, were associated with substantial institutional changes.

As an outcome of a new regulation introduced in 2004, the institutional structure of the Fund (previously structured as a General Secretariat) has been strengthened by reorganizing it as a General Directorate of the Prime Ministry. The General Directorate was affiliated to the newly established Ministry of Family and Social Policies in 2011. The SASF was established to work in conjunction with regional associations that are located in each sub-province. There are currently 973 local associations that receive a regular monthly budget from the SASF (Aytaç, 2014 Metin, 2011). The selection of beneficiaries is under the responsibility of these associations. The benefits are allocated on the basis of 'neediness', which is determined through a proxy-means test. The details of the proxymeans test (namely, poverty-scoring formula) are not disclosed by the SASF. Individual criteria are applied by every association to determine the neediness of beneficiaries. The executive committees formed under every association of the sub-province execute their decisions independently. The autonomy exercised by centrally appointed bureaucrats of the local executive committees leaves an ample room for discretion, particularly for political preferences, in determining eligibility of the benefits (Aytaç 2014, Adaman et al. 2007).

While these committees do not adhere to the norms in determining the neediness of beneficiaries, the law provides a tacit definition for the term 'needy'. The individuals who are not covered by any social security institution and do not have monthly income, or those with per capita income lower than one third of net minimum wage are considered as needy (Law 3294). This threshold is de jure the eligibility criteria for free health care beneficiaries (namely, green card holders). However, a nationalized and binding povertyscoring formula based on a settled threshold does not exist for other social transfers. While applicants with scores below a certain threshold (determined by local committees) become officially eligible, applicants with poverty scores above the threshold are not automatically excluded from consideration, and they can still be regarded eligible at the discretion of the executive committee (Aytaç 2014).

The benefits allocated by the SASF through the local Associations might be classified in four categories. First category focuses on the health benefits, which is provided by the Fund. It provides health-related equipment for individuals who are not covered by any social security institution, while the medicine and treatment costs are covered by the Green Card programme. The second category is concerned with the education benefits in kind, and includes contribution of school clothes and stationery supplies for the poor households with primary and secondary school children. The third category involves family allowances such as food stamps, fuel, support for repair and maintenance of households, and other 
housing benefits that are provided in cash. Last category aims at meeting the basic needs of the people suffering from natural disasters and providing aid for public food-banks.

Even though the bulk of the social assistance schemes is administered by the central governments or local authorities (municipalities), there are still non-negligible number of social assistance and social service programs provided by non-governmental, private and charity organizations. They do not qualitatively differ from the governmental programs described above Adaman et al. 2007. 


\section{Appendix B Tables}

\section{B.1}

Table: Dynamic Random Effects Probit Model:

Wooldridge's Estimator

(in Unbalanced Sample)

\begin{tabular}{|c|c|c|c|c|}
\hline & (1) & $(2)$ & (3) & (4) \\
\hline \multirow[t]{2}{*}{ Benefit receipt at $t-1$} & $2.280^{* * *}$ & $1.574^{* * *}$ & $1.553^{* * *}$ & $1.413^{* * *}$ \\
\hline & $(0.030)$ & $(0.080)$ & $(0.081)$ & $(0.092)$ \\
\hline \multirow[t]{2}{*}{ Benefit receipt at $t=1$} & & $1.288^{* * *}$ & $1.322^{* * *}$ & $1.646^{* * *}$ \\
\hline & & $(0.157)$ & $(0.160)$ & $(0.193)$ \\
\hline \multicolumn{5}{|l|}{ Personal characteristics } \\
\hline \multirow[t]{2}{*}{ Age } & $-0.048 * * *$ & $-0.062^{* * *}$ & $-0.063^{* * *}$ & 0.074 \\
\hline & $(0.012)$ & $(0.016)$ & $(0.016)$ & $(0.114)$ \\
\hline \multirow[t]{2}{*}{ Age square } & $0.000 * * *$ & $0.001 * * *$ & $0.001 * * *$ & -0.001 \\
\hline & $(0.000)$ & $(0.000)$ & $(0.000)$ & $(0.001)$ \\
\hline \multirow[t]{2}{*}{ Female } & 0.073 & 0.0626 & 0.0640 & $0.349^{*}$ \\
\hline & $(0.107)$ & $(0.139)$ & $(0.141)$ & $(0.188)$ \\
\hline \multirow[t]{2}{*}{ Years of schooling } & $-0.050 * * *$ & $-0.066 * * *$ & $-0.066 * * *$ & -0.076 \\
\hline & $(0.004)$ & $(0.006)$ & $(0.007)$ & $(0.052)$ \\
\hline \multirow[t]{2}{*}{ Spouse's education } & $-0.043^{* * *}$ & $-0.056 * * *$ & $-0.056 * * *$ & -0.028 \\
\hline & $(0.005)$ & $(0.006)$ & $(0.007)$ & $(0.042)$ \\
\hline \multirow[t]{2}{*}{ No. children } & 0.102 & $0.194^{* * *}$ & $0.135^{*}$ & 0.108 \\
\hline & $(0.063)$ & $(0.023)$ & $(0.074)$ & $(0.083)$ \\
\hline \multirow[t]{2}{*}{ Household size } & 0.019 & -0.007 & 0.054 & 0.097 \\
\hline & $(0.046)$ & $(0.017)$ & $(0.055)$ & $(0.070)$ \\
\hline \multirow[t]{2}{*}{ Poor health } & 0.060 & $0.239 * * *$ & 0.085 & 0.092 \\
\hline & $(0.055)$ & $(0.039)$ & $(0.064)$ & $(0.067)$ \\
\hline \multirow[t]{2}{*}{ Unemployed } & -0.158 & $0.328^{* * *}$ & -0.167 & -0.148 \\
\hline & $(0.097)$ & $(0.069)$ & $(0.112)$ & $(0.118)$ \\
\hline \multicolumn{5}{|l|}{ Time-averages } \\
\hline \multirow[t]{2}{*}{ Avg: no. children } & 0.050 & & 0.070 & 0.070 \\
\hline & $(0.065)$ & & $(0.076)$ & $(0.130)$ \\
\hline \multirow[t]{2}{*}{ Avg: household size } & -0.029 & & -0.067 & -0.060 \\
\hline & $(0.047)$ & & $(0.057)$ & $(0.108)$ \\
\hline \multirow[t]{2}{*}{ Avg: poor health } & $0.203^{* * *}$ & & $0.243^{* * *}$ & $0.337^{* * *}$ \\
\hline & $(0.066)$ & & $(0.082)$ & $(0.121)$ \\
\hline \multirow[t]{2}{*}{ Avg: unemployed } & $0.650 * * *$ & & $0.808 * * *$ & $0.844^{* * *}$ \\
\hline & $(0.116)$ & & $(0.146)$ & $(0.221)$ \\
\hline \multicolumn{5}{|l|}{ First-wave characteristics } \\
\hline \multirow[t]{2}{*}{ Fst: age } & & & & -0.157 \\
\hline & & & & $(0.115)$ \\
\hline Fst: age square & & & & 0.001 \\
\hline
\end{tabular}


Fst: years of schooling

(0.001)

0.002

(0.052)

Fst: spouse's education

$-0.0314$

(0.043)

Fst: no. children

0.056

(0.103)

Fst: household size

$-0.064$

(0.085)

Fst: poor health

$-0.081$

(0.086)

Fst: unemployed

0.021

(0.152)

$\begin{array}{lllll}\text { Constant } & -0.282 & -0.322 & -0.345 & -0.007\end{array}$

\begin{tabular}{lllll} 
& $(0.251)$ & $(0.331)$ & $(0.339)$ & $(0.397)$ \\
Year dummies & Yes & Yes & Yes & Yes \\
\hline$\sigma_{\alpha}$ & 0.001 & $0.775^{* * *}$ & $0.799^{* * *}$ & $0.932^{* * *}$ \\
& $(0.007)$ & $(0.079)$ & $(0.081)$ & $(0.089)$ \\
$\rho$ & 0.000 & $0.375^{* * *}$ & $0.390^{* * *}$ & $0.465^{* * *}$ \\
& $(0.000)$ & $(0.048)$ & $(0.048)$ & $(0.047)$ \\
Log likelihood & -5257.111 & -5217.207 & -5196.231 & -5029.375 \\
No. observations & 25,222 & 25,222 & 25,222 & 24,645 \\
No. individuals & 14,383 & 14,383 & 14,383 & 13,931 \\
\hline Persistence rate & $69.4 \%$ & $32.4 \%$ & $31.3 \%$ & $22.8 \%$ \\
Entry rate & $3.8 \%$ & $2.1 \%$ & $2.1 \%$ & $1.6 \%$ \\
Average partial effect & 65.6 & 30.3 & 29.2 & 21.2 \\
\hline \hline
\end{tabular}

Robust standard errors in parentheses. ${ }^{* * *} \mathrm{p}<0.01,{ }^{* *} \mathrm{p}<0.05,{ }^{*} \mathrm{p}<0.1$ 


\section{B.2}

Table: Dynamic Random Effects Probit Model: Heckman's Estimator (in Unbalanced Sample)

\begin{tabular}{|c|c|c|c|c|}
\hline & (1) & $\begin{array}{l}\text { (2) } \\
\text { initial cond. }\end{array}$ & (3) & $\begin{array}{l}\text { (4) } \\
\text { initial cond. }\end{array}$ \\
\hline Benefit receipt at $t-1$ & $\begin{array}{l}1.508^{* * *} \\
(0.076)\end{array}$ & & $\begin{array}{l}1.686^{* * *} \\
(0.087)\end{array}$ & \\
\hline \multicolumn{5}{|l|}{ Personal characteristics } \\
\hline Age & $\begin{array}{l}-0.062^{* * *} \\
(0.019)\end{array}$ & & $\begin{array}{l}-0.062^{* * *} \\
(0.017)\end{array}$ & \\
\hline Age square & $\begin{array}{l}0.001^{* *} \\
(0.000)\end{array}$ & & $\begin{array}{l}0.001^{* * *} \\
(0.000)\end{array}$ & \\
\hline Female & $\begin{array}{l}0.282 \\
(0.196)\end{array}$ & & $\begin{array}{l}0.275 \\
(0.176)\end{array}$ & \\
\hline Years of schooling & $\begin{array}{l}-0.105^{* * *} \\
(0.010)\end{array}$ & & $\begin{array}{l}-0.088^{* * *} \\
(0.010)\end{array}$ & \\
\hline Spouse's education & $\begin{array}{l}-0.084^{* * *} \\
(0.009)\end{array}$ & & $\begin{array}{l}-0.071^{* * *} \\
(0.008)\end{array}$ & \\
\hline No. children & $\begin{array}{l}0.107 \\
(0.080)\end{array}$ & & $\begin{array}{l}0.099 \\
(0.077)\end{array}$ & \\
\hline Household size & $\begin{array}{l}0.110 \\
(0.068)\end{array}$ & & $\begin{array}{l}0.102 \\
(0.065)\end{array}$ & \\
\hline Poor health & $\begin{array}{l}0.084 \\
(0.066)\end{array}$ & & $\begin{array}{l}0.076 \\
(0.063)\end{array}$ & \\
\hline Unemployed & $\begin{array}{l}-0.149 \\
(0.116)\end{array}$ & & $\begin{array}{l}-0.142 \\
(0.111)\end{array}$ & \\
\hline Time-averages & & & & \\
\hline Avg: no. children & $\begin{array}{l}0.224^{* *} \\
(0.085)\end{array}$ & & $\begin{array}{l}0.180^{* *} \\
(0.082)\end{array}$ & \\
\hline Avg: household size & $\begin{array}{l}-0.126^{*} \\
(0.071)\end{array}$ & & $\begin{array}{l}-0.118^{*} \\
(0.067)\end{array}$ & \\
\hline Avg: poor health & $\begin{array}{l}0.399 * * * \\
(0.088)\end{array}$ & & $\begin{array}{l}0.340^{* * *} \\
(0.083)\end{array}$ & \\
\hline Avg: unemployed & $\begin{array}{l}1.147^{* * *} \\
(0.164)\end{array}$ & & $\begin{array}{l}0.994^{* * *} \\
(0.111)\end{array}$ & \\
\hline First-wave characteristic & & & & \\
\hline Fst: age & & $\begin{array}{l}0.047^{* *} \\
(0.019)\end{array}$ & & $\begin{array}{l}0.040^{* *} \\
(0.018)\end{array}$ \\
\hline Fst: age square & & $\begin{array}{l}-0.001^{* * *} \\
(0.000)\end{array}$ & & $\begin{array}{l}-0.001^{* * *} \\
(0.000)\end{array}$ \\
\hline Fst: female & & $\begin{array}{l}-0.375^{*} \\
(0.211)\end{array}$ & & $\begin{array}{l}-0.382^{*} \\
(0.201)\end{array}$ \\
\hline Fst: years of schooling & & $-0.121^{* * *}$ & & $-0.108^{* * *}$ \\
\hline
\end{tabular}


Fst: spouse's education

Fst: no. children

Fst: household size

Fst: poor health

Fst: unemployed

Pre-sample characteristics

Pre: unemployed

Pre: poverty1

Pre: poverty2

Pre: poverty3

Constant

Year dummies

$\theta$

$\rho$

Log likelihood

No. observations

Persistence rate

Entry rate

Average partial effect

$(0.008)$
$-0.096^{* * *}$
$(0.008)$
$0.328^{* * *}$
$(0.030)$
0.025
$(0.021)$
$0.462^{* * *}$
$(0.052)$
$0.881^{* * *}$
$(0.090)$

$(0.009)$

$-0.090^{* * *}$

(0.008)

$0.308^{* * *}$

(0.029)

0.020

(0.020)

$0.396^{* * *}$

(0.050)

$0.470^{* *}$

(0.198)

$0.344^{*}$

(0.201)

$0.218^{* * *}$

(0.060)

$0.243^{* * *}$

(0.046)

$0.217^{* * *}$

(0.047)

0.452

$-2.181^{* * *}$

(0.353)

(0.401)

(0.395)

(0.417)

Yes

$0.028^{* * *}$

(0.140)

$-0.380$

(0.289)

$-10062.429$

25,222

$35.7 \%$

$2.0 \%$

33.7

Robust standard errors in parentheses. ${ }^{* * *} \mathrm{p}<0.01,{ }^{* *} \mathrm{p}<0.05,{ }^{*} \mathrm{p}<0.1$ 